\title{
Princípio da continuidade do serviço público essencial e a inadimplência do usuário
}

\author{
Principle of continuity of essential public service and default user
}

\author{
Fernanda Ferreira Ruiz ${ }^{1}$ \\ Patrícia Toledo de Campos ${ }^{2}$
}

\begin{abstract}
Resumo
0 texto analisa os serviços públicos essenciais sob a ótica do princípio constitucional da continuidade. Apresenta breve apreciação do histórico dos serviços públicos. Expõe o conceito do referido instituto, bem como de seus princípios reguladores. Aborda como principal objeto o princípio da continuidade dos serviços públicos, sua aplicação e consequências jurídicas. Enfatiza a hipótese de suspensão dos referidos serviços como consequência da inadimplência do usuário.
\end{abstract}

Palavras Chave: Serviços públicos essenciais; Princípios; Continuidade; Inadimplemento do usuário; Suspensão de serviços.

\begin{abstract}
This article analyzes the essential public services from the perspective of the constitutional principle of continuity. Presents a brief historical assessment of public services. Describes the concept of this institute and its guiding principles. Discusses the main object of the principle of continuity of public services, its aplication and legal consequences. Emphasizes the possibility of suspension of such services as a result of default by the user.
\end{abstract}

Keywords: Essential public services; Principles; Continuity; Default user; Services suspension.

\section{Introdução}

0 presente artigo busca apresentar a temática dos serviços públicos, instituto primordial do Direito Administrativo, de grande importância no contexto social e jurídico. 0 enfoque se dará sobre os serviços essenciais, sendo que o objetivo é demonstrar a ligação destes ao princípio da continuidade, especialmente em relação ao descumprimento do

\footnotetext{
${ }^{1}$ Graduanda da 4a série do curso de Direito/UEL.

${ }^{2}$ Graduanda da 4a série do curso de Direito/UEL.
} 
usuário de suas obrigações contratuais, e a possibilidade da suspensão desses serviços pelos prestadores.

Em um primeiro momento será exposto o histórico dos serviços públicos, no qual se demonstra como ocorreu a construção teórica e prática deste instituto, para melhor compreensão de sua importância e objetivo social, e da necessidade da prestação deste sobre a égide do Estado.

Analisado o desenvolvimento do instituto, será exposto o conceito legal e doutrinário de serviços públicos, hodiernamente visto como aquele estabelecido por lei e de responsabilidade do Estado, que tem o dever de prestá-lo, direta ou indiretamente. A justificativa da obrigatoriedade decorre do fato de que a Administração Pública reconhece estes serviços como essenciais para o desenvolvimento da sociedade, e para a possibilidade de vida digna de seus cidadãos.

Neste contexto, apreciará os diversos princípios reguladores dos serviços públicos de forma sucinta, frente à importância destes para preservação dos interesses da coletividade. A seguir, será exposta a classificação doutrinária da natureza dos serviços públicos em essenciais e não-essenciais e obrigatórios e facultativos. A distinção destes serviços se faz necessária para melhor análise do tema proposto.

A partir do entendimento da essência dos serviços públicos, será demonstrada a conexão deste com o princípio da continuidade, pelo qual estes serviços, especialmente os essenciais e obrigatórios, devem ser prestados de forma continua, não sendo admitida sua interrupção. Para melhor exame deste assunto, demonstrar-se-á a relação dos referidos pontos apreciando-os sob o princípio da dignidade humana, visto que a preservação deste é escopo do Estado, previsto na Carta Magna.

Para melhor análise do principio da continuidade, buscou-se informações trazidas pela melhor doutrina e jurisprudência, assim como a analogia desta com a legislação atual.

Neste sentido, discorrer-se-á sobre a possibilidade da suspenção dos serviços públicos pela inadimplência do usuário, assunto este objeto de grande divergência doutrinária. A hipótese de suspensão será analisada levando em conta a natureza dos serviços prestados, conforme a classificação anteriormente apresentada, demonstrando-se também os direitos tanto do usuário, como do prestador dos serviços, neste caso, o Estado ou seus delegados. 
Como fundamento deste assunto, serão expostas as opiniões doutrinárias, tanto dos administrativistas que são a favor da suspensão, quanto dos que condenam essa possibilidade, fazendo a oposição dos diversos argumentos que sustentam ambas as posições. Também será apresentado o posicionamento do STJ, assim como a legislação relativa a este assunto.

Por fim, serão feitas considerações sobre a responsabilidade pela suspensão dos serviços públicos essenciais. Como ocorrerá a responsabilização, tanto do Estado, como das delegatárias, e com base em quais fundamentos.

\section{Histórico}

O Direito Administrativo adveio de teses jurídicas francesas. As construções doutrinárias francesas referentes ao serviço público levaram os países latino-americanos a enraizar 0 início de suas realizações administrativas na grande potência civil Law, que é a França.

Calcados nos ideais republicanos, buscando igualdade e liberdade, a notícia de serviço público foi proporcionada pelo entusiasmo cultural e ideológico da Revolução Francesa. Dois grandes nomes de doutrinadores franceses se destacaram nesse período, Duguit e Jéze, fazendo que disseminasse a expressão serviço público, inicialmente tratada como simples teoria, no início do século XX.

O Direito Administrativo relaciona sua base na noção de serviço público, pois todas as suas regras são estabelecidas para a prestação de serviços públicos. Portanto, o referido instituto tem por finalidade, atender aos interesses gerais da sociedade. Como muito bem enunciado por Léon Duguit e Gaston Jéze, os fundadores da Escola do Serviço Público, o governante tem como incumbência a organização e o bom funcionamento dos serviços públicos, satisfazendo o bem-estar de seus administrados.

Léon Duguit acionou a máquina administrativa referente ao serviço público, tornando-se fundador da Escola do serviço público ou também chamada de Escola de Bordeaux. Duguit era seguidor das ideias do filósofo Durkheim, ambos fidelíssimos à sociologia jurídica, muito influenciada pelas ciências econômicas que atuaram no desenvolvimento do Direito e, consequentemente, na evolução conceitual de serviços públicos. 
Aragão (2008, p.81) afirma que

[...] Para Duguit 'a noção de serviço público substitui o conceito de soberania (puissance) como fundamento do Direito Público. Seguramente a noção de serviço público não é nova. Já no momento em que, por uma série de razões (...), se produziu a distinção entre governantes e governados, a noção do serviço público nasceu no espírito dos homens. Com efeito, a partir desse momento se compreendeu que há certas obrigações dos governantes para com os governados e que a realização desses deveres é, ao mesmo tempo, a consequência e o fundamento da sua força superior.

Para o referido autor, o Estado deveria se submeter a uma ordem objetiva originada por outrem e não pela vontade dos governantes, enfatizando, dessa maneira, a solidariedade social. Duguit entendia que 0 Direito não deveria se restringir às regras formais relativas à intervenção do Estado, em face de as normas serem apenas roteiros para guiarem uma sociedade.

Segundo 0 doutrinador francês, é a consciência da população que cria 0 Direito. Assim, no momento em que esta consente que pode ser organizada de uma maneira mais harmônica, ocorre a transformação da ordinária norma social em norma jurídica, pois ocorre a violação da noção de soberania estatal em face do descobrimento que o Estado não é somente instrumento para garantir segurança à população, mas também sujeito a cumprir obrigações, de acordo com as carências dos habitantes que residem em seu território.

Nesse diapasão é que Duguit (apud ARAGÃO, 2008, p. 83) desenvolveu a famosa Teoria dos Serviços Públicos, conceituando serviço público como

[...] toda atividade cujo cumprimento deve ser regulado, assegurado e fiscalizado pelos governantes, por ser indispensável à realização e ao desenvolvimento da interdependência social, e de tal natureza que só possa ser assegurado plenamente pela intervenção da força governante (...). Dizer que um serviço é um serviço público quer dizer que esse serviço é organizado pelos governantes, funcionando sob a sua intervenção e devendo ter por eles assegurado o seu funcionamento sem interrupção.

0 autor sugeria dois elementos ao definir serviço público: o primeiro era que 0 serviço público deveria incutir interdependência social e o segundo que, para o Estado interferir no interesse público, era necessário o déficit do mercado de gerir essa interdependência social. 
Medauar (2004, p. 372) leciona que o serviço público se mostra como ideia mestra do Direito Administrativo e do Estado, configurando a cooperação de serviços prestados à população de maneira organizada e concentrada no poder governamental.

Duguit, baseando-se em suas teorias estatais e jurídicas referente aos serviços públicos, enfatizou que estes não foram criados pelo Estado, mas sim pela sociedade, objetivando preencher carências essenciais da população, que só poderiam ser supridas se a própria sociedade, representada pelo Estado, as garantisse.

Outro ponto teórico do autor supramencionado é a forma de visualizar o serviço público de uma forma mais ampla, pois comparava o serviço público às demais atividades estatais, sejam elas legislativas, jurisdicionais ou administrativas, conceituando Estado como apenas um conjunto de serviços públicos organizados e fiscalizados pelos governantes, ou seja, seria serviço público qualquer atribuição do Poder Público, diferenciando tais atribuições somente no tocante à natureza da função (legislativa, administrativa ou judiciária).

Ainda na visão de Duguit o serviço público era o fenômeno de grande importância social que seria garantido pelo Estado, sem importar se a regência de tal instituto seria por normas públicas ou privadas. Este posicionamento levou Jéze a criticar seu companheiro, pois, em sua concepção, só seriam considerados serviços públicos aqueles realizados pelo regime jurídico de Direito Público.

Gaston Jéze, também fundador da Escola de Bordeaux, discordando de vários dos entendimentos de Duguit, posicionou-se firmemente na concepção stricto sensu dos serviços públicos, abandonando a concepção sociológica de seu mestre e conceituando tal instituto como sendo atividades prestadas sob o regime jurídico de Direito Público. Para ele, as atividades de interesse comum são de exclusividade do Estado, porém, algumas podem ser prestadas também, de maneira exclusiva ou subsidiária, pela iniciativa privada, sob a égide do regime jurídico de Direito Privado.

Para Jéze (apud ARAGÃO, 2008, p. 87) ter-se-á serviço público quando se

[...] satisfazer regular e continuamente determinada categoria de necessidades de interesse público, há um regime jurídico especial, que sempre pode ser modificado pelas leis e pelos regulamentos. Todas as vezes que se está diante de um serviço público propriamente dito, se constata e existência de regras jurídicas especiais, que têm por objeto facilitar o funcionamento regular e contínuo do serviço público, 
de dar a mais rápida e completa possível satisfação às necessidades de interesse público; e essas regras, justamente por essas razões, são modificáveis a qual quer instante (...). Em suma, o serviço público é um mecanismo - e não apenas o único mecanismo - para satisfação de necessidades de interesse público, o que significa que teorias e regras especiais são aplicáveis, que há um regime jurídico especial, regime jurídico esse que é legal e regulamentar.

O regime jurídico especial do serviço público será determinado pelas circunstâncias públicas impostas aos particulares e pela possibilidade que o Estado possui de estabelecer taxas com a finalidade de garantir a prestação do serviço. Jéze exemplifica serviços públicos com a fabricação da pólvora, de cigarros e de fósforos, atualmente monopolizados pelo Estado francês, pois a cada momento em que se está na presença de um serviço público, se atesta a existência de um regime jurídico de Direito Público. Jéze possuía como postulado o fato de o serviço público ser regido por regime especial de Direto Público, porque somente assim $o$ interesse público prevaleceria sobre 0 interesse privado.

Destarte, pode-se inferir que, como muito bem enuncia Gasparini (2004, p. 276), para Gaston Jéze a prestação do serviço público é única, já para Léon Duguit é a primordial atividade da Administração Pública.

Apesar da esplêndida e inaugural colaboração dos doutrinadores franceses, é importante ressaltar que a Escola do Serviço Público, na pessoa de seus responsáveis Duguit e Jéze, hodiernamente está sendo objeto de muitas críticas pela doutrina.

\section{Conceito}

A respeito da conceituação de serviços públicos, cumpre salientar que não há um consenso doutrinário, todavia, existem escolas e correntes teóricas que buscam revelar e caracterizar uma atividade como serviço público.

Na busca de esmiuçar e alcançar uma definição para tal instituto, Gasparini (2004, p. 277) afirma que

[...] Não é fácil oferecer a noção de serviço público. A doutrina toma essa locução nas mais variadas acepções e com isso dificulta a obtenção da almejada uniformidade conceitual. Tal verificação levou Waline a dizer, sobre a busca desse desejado conceito, trata-se de um "diálogo de surdos", e a preconizar-se, na França, a "crise da noção de serviço público". 
Como já foi mencionado, de acordo com Duguit, o serviço público seria qualquer atribuição do Poder Público, diferenciando-se tais atribuições somente no tocante à natureza da função (legislativa, administrativa ou judiciária). Muitos doutrinadores que não partilhavam dessa concepção, na busca de definir essa atividade pública afirmaram:

[...] desde já devemos, excluir do conceito de serviço público as atividades legislativas (edição de normas gerais e abstratas pelo Poder Legislativo) e jurisdicionais (composição definitiva de conflitos), voltando-se a pesquisa doravante apenas às atividades administrativas (ARAGÃO, 2008, p. 130).

Portanto, partindo do pressuposto que serviços públicos são apenas atividades administrativas, ou seja, que a titularidade do serviço público sempre é do Estado, a doutrina majoritária conceitua o referido instituto sob a égide de critérios materiais, formais e subjetivos como sendo elementos úteis ou necessários à identificação ou definição dos serviços públicos, como muito bem esclarece os autores Alexandrino e Paulo (2010, p. 624).

No que tange à definição do serviço público em sentido subjetivo e em sentido objetivo, pode-se afirmar que quando a expressão "serviço público" é utilizada em sentido subjetivo, na verdade, refere-se ao conjunto de órgãos e entidades que realizam funções administrativas das mais variadas, ou seja, todo o aparelhamento administrativo. Quando a expressão "serviço público" está empregada em sentido objetivo refere-se a uma atividade certa e não a caracterização de pessoas ou órgãos que realizam essas atividades.

Para o doutrinador M ello (2003, p. 623), a noção de serviço público deve se compor de dois elementos: o substrato material, que consiste na prestação de utilidade ou comodidade fruível singularmente pelos administrados, e também por um elemento formal caracterizador do serviço público que é seu regime jurídico, pois há a necessidade de submissão a um regime de Direito Público que conferirá caráter jurídico à noção de serviço público.

Ainda para o referido autor

[...] Quanto ao primeiro elemento - seu substrato material -, cumpre observar que a atividade estatal denominada serviço público é a prestação consistente no oferecimento, aos administrados em geral, de utilidades ou comodidades materiais (como água, luz, gás, telefone, transporte coletivo etc.) singularmente fruíveis pelos administrados que o Estado assume como próprias, por serem reputadas imprescindíveis, necessárias ou apenas correspondentes a conveniências básicas da Sociedade. (...) O segundo elemento, formal, isto é, a submissão a um regime de 
Direito Público, o regime jurídico-administrativo, é que confere caráter jurídico à noção de serviço público. Sua importância, pois é decisiva (2003, p. 624- 625).

Na concepção de Mello, pode-se compreender o aspecto subjetivo como sendo todo serviço prestado pela Administração ou por seus delegados, sob normas e controles estatais, para satisfazer necessidades essenciais ou secundárias da coletividade, ou simples conveniências do Estado. Refere-se às pessoas que atuam, abrangendo todas as atividades exercidas pela Administração Pública.

A criação e a gestão dessas atividades são executadas por lei e incumbidas ao Estado, que pode fazê-lo diretamente, pela própria administração direta ou pela administração direta, se utilizando da descentralização por outorga (também chamada descentralização por serviços, através da qual o Estado cria uma pessoa e transfere a ela a execução do serviço) ou por delegação (também chamada descentralização por colaboração, pela qual a administração transfere a execução do serviço a uma pessoa já existente, inclusive pessoas de direito privado).

Assim, tem-se que num sentido objetivo, material, serviço público é aquele que a própria lei estabelece como serviço público, tendo, portanto, caráter de regime jurídico de direito público, composto por princípios e regras caracterizadas pela supremacia do interesse público sobre o particular e por restrições parciais.

Medauar (2004, p. 374), na busca de conceituar serviços públicos, inferiu que a essência de tal instituto é a prestação, ou seja, a realização de atividades praticadas pelo Estado que possibilitam regalias e bens aos administrados. Para a autora, essas atividades pressupõem alguns elementos, como o vínculo orgânico com a Administração e a submissão total ou parcial ao direito administrativo, mostrando-se adepta do doutrinador francês J éze, ao afirmar que a atividade

[...] mesmo que seja realizada por particulares, em tese sujeita a regras do direito privado, se a atividade for qualificada como serviço público, tem notas de diferenciação; não há serviços públicos submetidos exclusivamente ao direito privado (...) o serviço público não acarreta necessariamente a aplicação exclusiva do direito público, mas é condição suficiente da aplicação de certo "quantum" de direito administrativo.

Portanto, vale salientar, novamente, que há divergências doutrinárias no que tange ao conceito de serviços públicos. Para Alexandrino e Paulo (2010, p. 627). 
[...] 0 critério subjetivo ou orgânico dá relevância ao prestador do serviço público; só considera serviço público aquele prestado diretamente pelos órgãos e entidades paraestatais, integrantes da administração pública. Já o critério material confere relevância à atividade, em si mesma considerada; as atividades de importância crucial para o grupo social, das quais depende a própria existência deste, devem ser tidas por serviço público; as atividades que visam à satisfação de necessidades coletivas fundamentais deveriam, portanto, ser prestadas como serviço público e 0 critério formal dá relevância ao regime jurídico sob o qual é desenvolvida a atividade; exige que os serviços públicos sejam prestados sob regime jurídico de direito público, portanto, orientados pelo princípio da supremacia do interesse público e pelo princípio da indisponibilidade do interesse público.

Para Gasparini (2004, p. 278), serviço público é toda atividade de oferecimento de utilidade preponderantemente pelos administrados, prestada pela Administração Pública ou por quem Ihe faça às vezes, sob um regime de Direito Público, instituído em favor de interesses definidos como próprios pelo ordenamento jurídico.

Aragão (2008, p. 157), em sua obra Direito dos Serviços Públicos, buscou esgotar a conceituação do instituto dos serviços públicos, e, à luz da Constituição de 1988, definiu-o como

[...] atividades de prestação de utilidades econômicas a indivíduos determinados, colocadas pela Constituição ou pela Lei a carga do Estado, com ou sem reserva de titularidade, e por ele desempenhadas diretamente ou por seus delegatários, gratuita ou remuneradamente, com vistas ao bem-estar da coletividade.

Para finalizar, a doutrinadora Di Pietro (2010, p. 102), após várias indagações e reflexões, conceituou serviços públicos de uma maneira clara e sucinta como sendo

[...] toda atividade material que a lei atribui ao Estado para que a exerça diretamente ou por meio de seus delegados, com o objetivo de satisfazer concretamente às necessidades coletivas, sob regime jurídico total ou parcialmente público.

Logo, após várias conceituações, infere-se que serviços públicos são aqueles que a Administração Pública realiza, direta ou indiretamente, para a comunidade em razão de reconhecê-los como essenciais para a perpetuação da sociedade e também do próprio Estado, através do procedimento típico do Direito Público. 


\section{Princípios reguladores do serviço público}

Analisado o conceito de serviços públicos, verifica-se a importância deste instituto no âmbito social e jurídico, motivo pelo qual é de suma importância que estes serviços se desenvolvam sob a égide de determinados princípios, buscando desta forma que os objetivos deste instituto não se corrompam e sejam eficazes, preservando-se o interesse da coletividade.

De acordo com os ensinamentos de Di Pietro (2010, p.62), citando José Cretella Júnior, "princípios de uma ciência são as proposições básicas, fundamentais, típicas que condicionam todas as estruturações subsequentes. Princípios, neste sentido, são os alicerces da ciência".

0 regime jurídico dos serviços públicos baseia-se nos princípios gerais da administração pública previstos no artigo $37 \mathrm{da} \mathrm{CF} / 88$, sendo estes, o princípio da legalidade, impessoalidade, moralidade, publicidade e eficiência. Além destes, há incidência de princípios específicos, quais sejam, segundo a classificação de Di Pietro (2010, p.107), o da mutabilidade do regime jurídico, da igualdade dos usuários e da continuidade dos serviços públicos.

Sobre a mutabilidade do regime jurídico cumpre dizer que é o princípio pelo qual a forma de execução de determinado serviço pode ser alterada, com fundamento no interesse público, para melhor adequação dos meios aos fins desejados pela administração pública, até mesmo de forma unilateral por esta. 0 regime jurídico de execução inicialmente aplicado pode sofrer variações durante o decorrer do tempo do serviço, porém, importa dizer que 0 equilíbrio econômico-financeiro deve sempre ser preservado no contrato de prestação (SPITZCOVSKY, 2004, p.111).

O princípio da igualdade dos usuários de serviços públicos, correspondente ao da impessoalidade previsto no artigo 37 da Constituição Federal de 1988, pressupõe que todos os indivíduos da sociedade que usufruem desses serviços, uma vez satisfeitas as condições legais estabelecidas, devem ser tratados igualitariamente, de forma que não ocorram discriminações entre os destinatários.

Sobre a continuidade dos serviços públicos, importa dizer em um primeiro momento, que se trata de princípio de grande importância teórica e prática, pelo qual o 
serviço público não deve ser interrompido, sendo necessário que sua execução seja contínua.

Ressalte-se ainda a existência de outros princípios enumerados pela Lei 8987/95 em

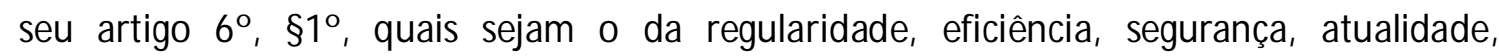
generalidade, cortesia na sua prestação e modicidade de tarifas.

\section{Serviços públicos essenciais e o princípio da continuidade}

Serviços públicos, como já analisado, são aqueles atribuídos por lei ao Poder Público, constituindo finalidade de sua prestação a consecução das necessidades sociais. Portanto é dever inescusável do Estado promover-Ihes a execução, sendo submetidos ao regime jurídico de direito público. Esta obrigação se fundamenta no dispositivo constitucional pelo qual o Poder Público deve realizar a prestação de serviços públicos de forma direta ou indireta, por meio do regime de concessão ou permissão, conforme o disposto na lei (art. 175 da CF).

Registre-se, entretanto, que mesmo sob a forma de delegação, o serviço não será descaracterizado como público, "vez que o Estado sempre se reserva o poder jurídico de regulamentar, alterar e controlar o serviço" (CARVALHO FILHO, 2009, p.310).

Os serviços públicos podem ser caracterizados em essenciais e não-essenciais. Segundo Carvalho Filho (2009, p. 310) os serviços essenciais são aqueles que visam à satisfação das principais demandas da sociedade, por esse fato devem ser prestados pelo Estado com a maior amplitude possível. Os não-essenciais são entendidos como aqueles que por algum motivo especial merecem avaliação do Poder Público, buscando-se atender as necessidades coletivas. 0 doutrinador ainda explica

[...] o caráter de essencialidade do serviço não tem parâmetros previamente definidos, variando de acordo com o lugar e o tempo em que a atividade é desempenhada. Com efeito, há países em que um determinado serviço se configura como essencial, ao passo que em outro não passa de atividade secundária.

Outra importante classificação é a trazida por Aragão (2008, p. 551), que distingue serviços públicos obrigatórios e facultativos. 
Serviços públicos facultativos são aqueles que o cidadão pode escolher ser usuário do serviço ou satisfazer determinada necessidade através de outro meio, como exemplo tem-se a energia elétrica, que pode ser provida através de um serviço público ou através de vias alternativas, como um gerador.

Serviços públicos obrigatórios são aqueles impostos a todos os cidadãos por conta de sua elevada importância, são serviços que resguardam interesses sociais. Não há, neste caso, opção por parte do usuário de utilizar-se de outra forma para satisfazer determinada necessidade que não seja pelo serviço público. 0 doutrinador traz como exemplo de serviço público obrigatório o da coleta de lixo domiciliar, não podendo o particular se livrar do seu lixo de outra forma que não seja pela utilização deste serviço.

Merece destaque a afirmação de Aragão (2008, p.533), para quem "os serviços públicos não são em si um direito fundamental, mas meios de realização de direitos fundamentais autonomamente considerados".

Frente à importância da prestação destes serviços, que garantem, segundo o mesmo autor, que os cidadãos tenham o básico para que possam viver de forma digna, é necessário que o Estado forneça a prestação dos serviços públicos de forma ininterrupta. Neste sentido temos o princípio da continuidade garantido no ordenamento jurídico.

0 princípio da continuidade consiste na necessidade de que os serviços públicos sejam executados sem serem interrompidos. Este princípio gera inúmeros reflexos de ordem prática principalmente em relação à possibilidade de suspensão dos serviços públicos.

Em observância deste princípio, o legislador achou por bem regulamentar a execução dos serviços públicos no art. 22 do Código do Consumidor (CDC), o qual traz como regra a impossibilidade da suspensão desses serviços nos seguintes termos:

[...] os órgãos públicos, por si ou suas empresas, concessionárias, permissionárias ou sob qualquer outra forma de empreendimento, são obrigados a fornecer serviços adequados, eficientes, seguros e, quanto aos essenciais, contínuos.

Impondo ainda em seu parágrafo único que, caso descumpridas estas obrigações pelas pessoas jurídicas responsáveis, de forma total ou parcial, serão elas compelidas a cumpri-las e ainda a reparar os danos causados.

Deve-se ainda observar a norma prevista na Lei $8987 / 95$, em seu artigo $6^{\circ}$, $§ 1^{\circ}$, pelo qual as concessões e permissões devem ter como pressuposto que 0 serviço prestado seja 
adequado ao pleno atendimento dos usuários, considerando serviço adequado aquele que satisfaz, entre outras condições, a de continuidade.

\section{Suspensão do serviço público essencial pela inadimplência do usuário}

Como já exposto, a prestação do serviço público é dever do Estado e o recebimento deste é direito fundamental do usuário. No entanto, mesmo perante o princípio da continuidade e das regulamentações legais, há divergências doutrinárias quanto à possibilidade da incidência de suspensão sobre o serviço público em razão do inadimplemento do usuário.

Primeiramente, deve-se analisar a questão da suspensão do serviço público levando em conta sua natureza. Carvalho Filho (2009, p.318), assim como Aragão (2008, p.552), entende que caso o serviço tenha natureza de obrigatório, não é possível que haja suspensão deste mesmo diante do não pagamento pelo usuário, uma vez que este não tem opção com relação à contratação do serviço. Leva em consideração, neste sentido, que caso o serviço fosse interrompido, poderia ocorrer prejuízo para a coletividade e não só para o indivíduo.

Porém, em relação aos serviços públicos de natureza facultativa, há divergência doutrinária e jurisprudencial com relação à possibilidade de suspensão do serviço em caso de inadimplemento.

Para alguns doutrinadores, não é possível que haja a suspensão da prestação do serviço, mesmo que haja a falta de pagamento. Como fundamento desta posição temos o disposto no artigo 22 do CDC e ainda 0 art. 1ำ, inciso III da Constituição Federal, entendendo, portanto, que a prestação de serviços públicos essenciais é necessária para que se alcance a dignidade da pessoa humana, provendo condições mínimas de vida digna à coletividade.

Nesse sentido, Mello (2004, p.626) afirma que além de princípio regulador dos serviços públicos, a continuidade configura direito dos administrados, usuários dos serviços. De acordo com Hely Lopes M eirelles, citado na obra de Aragão (2008, p.540),

[...] os direitos do usuário são hoje reconhecidos em qualquer serviço público ou de utilidade pública como fundamento para a exigibilidade de sua prestação nas condições regulamentares e em igualdade com os demais utentes. São direitos cívicos, de conteúdo positivo, consistentes no poder de exigir da Administração ou 
de seu delegado o serviço que um ou outro se obrigou a prestar individualmente aos usuários.

Em sintonia com este entendimento temos a seguinte jurisprudência:

[...] ADM INISTRATIVO. M ANDADO DE SEGURANÇA. ENERGIA ELÉTRICA. AUSÊNCIA DE PAGAM ENTO DE TARIFA. CORTE. IM POSSIBILIDADE.

1. É condenável 0 ato praticado pelo usuário que desvia energia elétrica, sujeitando-se até a responder penalmente. 2. Essa violação, contudo, não resulta em reconhecer como legítimo ato administrativo praticado pela empresa concessionária fornecedora de energia e consistente na interrupção do fornecimento da mesma. 3. A energia é, na atualidade, um bem essencial à população, constituindo-se serviço público indispensável subordinado ao princípio da continuidade de sua prestação, pelo que se torna impossível a sua interrupção. 4. Os arts. 22 e 42, do Código de Defesa do Consumidor, aplicam-se às empresas concessionárias de serviço público. 5 . 0 corte de energia, como forma de compelir o usuário ao pagamento de tarifa ou multa, extrapola os limites da legalidade. 6 . Não há de se prestigiar atuação da Justiça privada no Brasil, especialmente, quando exercida por credor econômica e financeiramente mais forte, em largas proporções, do que 0 devedor. Afronta, se assim fosse admitido, aos princípios constitucionais da inocência presumida e da ampla defesa. 7. 0 direito do cidadão de se utilizar dos serviços públicos essenciais para a sua vida em sociedade deve ser interpretado com vistas a beneficiar a quem deles se utiliza. 8. Recurso improvido. (STJ, 1a Turma, ROM S n. 8915/MA, rel. M in. José Delgado, DJU de 17.8.1998).

Em sentido contrário, alguns doutrinadores entendem que é possível a suspensão em caso de inadimplemento baseando-se na lei 8987/95, que traz em seu artigo 6ㅇ, §3que não fica caracterizada a descontinuidade do serviço quando houver a sua interrupção em situação de emergência ou após aviso prévio, desde que motivada por razões de ordem técnica, ou de segurança das instalações, ou por inadimplemento do usuário, considerado o interesse da coletividade.

Dispositivo este, utilizado como fundamento para o atual posicionamento do ST] sobre a possibilidade da suspensão do serviço de energia elétrica quando não houver pagamento é pela possibilidade do corte do serviço, segundo o que se extrai do julgamento do Recurso Especial n. 363.943-MG, que traz em sua ementa:

[...] ADMINISTRATIVO - ENERGIA ELÉTRICA - CORTE - FALTA DE PAGAMENTO. É licito à concessionária interromper o fornecimento de energia elétrica, se, após aviso prévio, o consumidor de energia elétrica permanecer inadimplente no pagamento da respectiva conta. 
Entende-se desta forma que, como regra, não pode haver a descontinuidade do serviço público, porém quando houver alguma das causas prevista no artigo em foco, a interrupção poderá ocorrer. A exceção a regra abrange unicamente as situações de emergência e de inadimplemento, mediante aviso prévio. Ocorrendo alguma destas hipóteses, na opinião de Spitzcovsky (2004, p.181),

[...] 0 corte do fornecimento não representa descontinuidade da sua prestação e, por via de conseqüência, não sujeita o Poder Público a nenhum tipo de responsabilização, ainda que tenham sido caracterizados prejuízos aos seus usuários.

Porém, M ello (2004, p. 733) afirma que em relação ao artigo 60 , §3ำ da lei 8987/95, no qual o legislador traz a possibilidade de interrupção sem caracterizar a descontinuidade, este se preocupou em colocar uma cautela no final do dispositivo, qual seja "considerado o interesse da coletividade". No entanto, segundo o administrativista, a redação do artigo leva à conclusão que existem casos pelos quais não é possível a interrupção do serviço, mesmo que caracterizada a falta de contribuição. Como exemplo das hipóteses em que seria inadmissível a interrupção, temos o citado pelo referido doutrinador que traz que os serviços de água e luz, mesmo quando prestados por concessionárias, não podem ser cortados em um hospital ou em estabelecimentos carcerários.

Segundo Spitzcovsky (2004, p.181-182), há contradição entre 0 art. 6ํ, §3ํ da lei 8987/95 e 0 art. 22 do CDC. A possibilidade trazida pela lei para o corte do fornecimento do serviço, desde que o usuário não cumpra com sua obrigação e seja avisado previamente, deixa em segundo plano a importância do serviço público, uma vez que para o corte não se é averiguado se o serviço em questão é essencial ou não. Dessa forma, fere-se o disposto no artigo 22 do CDC pelo qual os serviços essenciais devem ser contínuos.

Neste caso, aqueles que defendem a suspensão alegam que a modalidade de prestação de serviço por concessão tem lei reguladora específica, portanto, o dispositivo a ser aplicado deve ser 0 artigo 60 da Lei das Concessões e não 0 artigo 22 do CDC.

0 doutrinador Aragão (2208, p. 552) tem posicionamento favorável à suspensão, ensinando que a prestação do serviço público de forma contínua tem como base uma relação de lealdade e boa-fé entre o prestador e o usuário do serviço, sendo necessário que ambas as partes cumpram com sua parte no acordo, que o prestador forneça o serviço e que 
o usuário pague a contraprestação. Não é possível que seja cobrada a prestação de serviço quando o usuário for inadimplente, pois se isso acontecesse não existiria equidade e 0 prestador seria prejudicado. 0 doutrinador explica que

[...] Se o concessionário fosse obrigado a tanto, nem estaríamos mais diante de uma concessão de serviço público, mas de requisição de serviços, pois a empresa estaria simplesmente sendo forçada a prestar serviços gratuitamente em razão do interesse público, o que escapa a qualquer idéia de marco contratual de concessão.

Temos neste sentido o julgamento do Recurso Especial n. 628.833/2004 pelo STJ, do qual segue a ementa:

[...] ADMINISTRATIVO. SUSPENSÃO DO FORNECIMENTO DE ENERGIA ELÉTRICA. INADIM PLÊNCIA. PREVISÃO LEGAL. CONTRATO SINALAGM ÁTICO.

I - $O$ contrato estabelecido entre 0 fornecedor de energia elétrica e o usuário é sinalagmático concluindo-se que o contratante só pode exigir a continuidade da prestação a cargo do contratado quando estiver cumprindo regularmente a sua obrigação. II - A suspensão do fornecimento de energia elétrica pode ocorrer em diversas hipóteses inclusive quando houver negativa de pagamento por parte do usuário. Tal convicção encontra assento no artigo 91 da Resolução no 456/2000 da Agência Nacional de Energia Elétrica. II - "É lícito à concessionária interromper 0 fornecimento de energia elétrica, se, após aviso prévio, o consumidor de energia elétrica permanecer inadimplente no pagamento da respectiva conta (L. 8.987/95, Art. 60, § 3ㅇ, II)". (REsp no 363.943/MG, Relator Ministro HUMBERTO GOMES DE BARROS, DJ de 01/03/2004, p. 119) IV - Recurso especial provido.

Alguns doutrinadores ainda afirmam que quando há a inadimplência do usuário sem a interrupção do serviço, este valor terá que ser arcado de alguma forma. Segundo Aragão (2008, p. 550-551) o débito será pago “ou por subsídio interno, onerando-se os usuários adimplentes, ou por um subsidio externo, com o Erário Público, ou seja, toda a sociedade cobrindo os prejuízos do concessionário com o inadimplemento".

Já na opinião de Mello (2004, p. 734), este defende a não suspensão do serviço público essencial nas seguintes palavras

[...] Em nosso entender, tratando-se de serviço de uma essencialidade extrema, como é o caso da água, de notória relevância para a saúde pública, ou mesmo de grande importância para a normalidade da vida atual, como os de eletricidade, nem o Poder Público ou o concessionário poderão cortá-los, se o usuário demonstrar insuficiência de recursos para o pagamento das contas mensais. Em tal caso, sua cobrança terá de ser feita judicialmente e, só aí, uma vez sopesadas as circunstancias pelo juiz, é que caberá ou não o corte a ser decidido nesta esfera. 
0 doutrinador ainda ensina que não se pode resolver a questão da suspensão dos serviços públicos observando-se unicamente as leis ordinárias, é necessário que esta seja interpretada à luz da Constituição e de seus preceitos fundamentais, considerando-se os direitos do cidadão e sua dignidade.

\section{Responsabilidade pela suspensão do serviço público essencial}

0 direito de recebimento da prestação do serviço público é garantido através de ação judicial. Deste modo, caso haja omissão do Estado para a execução de tais serviços, ou se estes não forem fornecidos de forma adequada, o usuário poderá se utilizar da via judicial idônea para que este seja compelido a atuar conforme suas obrigações, ou até mesmo, para que este seja responsabilizado por danos causados pela sua omissão (M ello, 2004, p.626).

A ação será proposta em face da entidade responsável pelo serviço recusado, ou seja, o Poder Público ou o concessionário. Contudo, nas situações de suspensão da prestação do serviço público essencial em caso de inadimplemento do usuário, existe discussão na doutrina sobre a possibilidade de responsabilização da empresa concessionária, por conta da violação do princípio da dignidade da pessoa humana.

Parte da doutrina entende que nesta situação não pode haver responsabilização da delegatária com fundamento na dignidade da pessoa humana, mas somente a responsabilização do Poder Público. Nesse sentido, os doutrinadores afirmam que a competência originária de prestação de serviços essenciais é do Estado. Quando o Ente Público decide promover a execução de serviço público sob a forma de concessão, realiza-se um contrato entre este e a empresa delegatária no qual contém todas as obrigações que são assumidas voluntariamente pelo delegatário (Aragão, 2008, p. 546-547).

Portanto, a obrigação da empresa prestadora do serviço público se restringe ao cumprimento dos termos contratados, não sendo possível ampliar as obrigações desta, de forma que seja forçada a prestar o serviço, ou responder por danos causados na ausência deste quando existir o inadimplemento, sem que haja o adequado reequilíbrio econômicofinanceiro da equação econômica inicial.

Nas palavras de Aragão (2008, p. 546-547) 
[...] é apenas dentro do marco regulatório (constitucional, legal, regulamentar ou contratual) da concessão que o concessionário estará obrigado a cumprir obrigações (ou, simetricamente, ter direitos), salvo repactuamento do trato inicial que mantenha a equação econômica inicial.

Em todo caso, nas hipóteses de suspensão em que houver ocorrido dano ao destinatário, o Poder Público poderá ser responsabilizado, uma vez que por preceito constitucional este é responsável para execução destes serviços e pela garantia dos direitos da coletividade, em especial pela condição de dignidade da pessoa humana. Pode inclusive ser utilizado o mandado de segurança em face do Ente Público, quando presentes os requisitos de direito líquido e certo.

A sentença proferida em favor do usuário terá natureza executiva, sendo possível compelir a entidade responsável a prestar o serviço. Ainda há possibilidade de ser definida indenização em favor da parte que sofreu eventual prejuízo pela suspensão, quando desta decorrer qualquer tipo de dano para o usuário (CARVALHO FILHO, 2009, p. 326).

\section{Conclusão}

O trabalho teve como objetivo abordar os serviços públicos essenciais, com ênfase no princípio da continuidade do serviço público essencial e o inadimplemento do usuário.

Através de pesquisa sobre o referido tema, objetivou-se aprofundar 0 entendimento sobre a proteção oferecida pelo Estado à coletividade, entidade indispensável para o corpo social, uma vez que é da coletividade, em específico, que se verifica o indivíduo em sua essência.

De acordo com os princípios específicos que também regem o regime jurídico administrativo é possível averiguar a existência de dois princípios fundamentais: o princípio da igualdade dos usuários de serviços públicos, bem como o da continuidade dos serviços públicos.

Após um breve histórico da origem dos serviços públicos, pode concluir que os serviços públicos são aqueles atribuídos por lei ao Poder Público, constituindo finalidade de sua prestação a consecução das necessidades sociais.

Abordou-se a suspensão do serviço público essencial pela inadimplência do usuário, apresentando inúmeras divergências doutrinárias, bem como jurisprudências contra e a 
favor; ademais, foram apresentadas explicações acerca da responsabilidade pela suspensão do serviço público essencial.

Enquanto alguns doutrinadores acreditam que a suspensão do serviço público, em qualquer hipótese, poderia acarretar prejuízo não só para o indivíduo, mas também para a coletividade, outros afirmam que não fica caracterizada a descontinuidade do serviço quando houver a sua interrupção em situação de emergência ou após aviso prévio, desde que motivada por razões de ordem técnica, ou de segurança das instalações, ou por inadimplemento do usuário, considerado o interesse da coletividade.

Diante 0 exposto, pode-se analisar as minúcias dos serviços públicos essenciais, concluindo que não se pode resolver a questão da suspensão dos serviços públicos observando-se unicamente as leis ordinárias, mas é necessário que estas sejam interpretadas à luz da Constituição e de seus preceitos fundamentais, considerando-se os direitos do cidadão, e sua dignidade.

\section{Referências}

ALEXANDRINO, Marcelo; PAULO, Vicente. Direito Administrativo Descomplicado. Rio de Janeiro: Forense; São Paulo: M étodo, 2010.

ARAGÃo, Alexandre Santos de. Direito dos serviços públicos. 2ª edição. Rio de Janeiro: Forense, 2008.

CARVALHO FILHO, José dos Santos. Manual de Direito Administrativo. 22a edição. Rio de Janeiro: Lumen Juris, 2009.

DI PIETRO, Maria Sylvia Zanella. Direito Administrativo. 23ạ edição. São Paulo: Atlas, 2010.

GASPARINI, Diógenes. Direito Administrativo. São Paulo: Saraiva, 2004.

M EDAUAR, Odete. Direito Administrativo M oderno. São Paulo: Revista dos Tribunais, 2004.

M ELLO, Celso Antonio Bandeira de. Curso de Direito Administrativo. M alheiros: 2003.

PEREIRA, Marcelo. A ESCOLA DO SERVIÇO PÚBLICO. Revista Diálogo Jurídico. Salvador, n. 11, 2002. Disponível em

বhttp:// www.buscalegis.ufsc.br/revistas/index.php/buscalegis/article/viewFile/19884/1944 8>-Acesso em: 11/09/2010>.

. Curso de Direito Administrativo. 25a edição. M alheiros: 2004. 
SPITZCOVSKY, Celso. Direito Administrativo. 6ạ edição. São Paulo: Damásio de Jesus, 2004.

Artigo recebido em:

24 de fevereiro de 2011

Artigo aprovado em:

06 de setembro de 2011 